\title{
STUDY OF MATERNAL OUTCOME IN WOMEN WITH FIRST TRIMESTER VAGINAL BLEEDING- A COMPARATIVE ANALYSIS
}

\author{
Phalguni Kangjam¹, Shalini Baghel2, Usharani Akoijam³ \\ 1 Junior Consultant, Acme Fertility and Healthcare Centre, Imphal, Manipur. \\ ${ }^{2}$ Senior Resident, Department of Obstetrics and Gynaecology, S. N. Medical College, Agra, Uttar Pradesh. \\ ${ }^{3}$ Assistant Professor, Department of Obstetrics and Gynaecology, RIMS, Imphal, Manipur.
}

\begin{tabular}{l}
\hline ABSTRACT \\
\hline BACKGROUND \\
One of the most common obstetric problems occurring in first trimester is vaginal bleeding. It accounts for majority of admissions \\
and it is a very common reason for ultrasound examination in early pregnancy. First trimester vaginal bleeding occurs in about \\
$25 \%$ of all pregnant women. \\
Objective- Comparison of maternal outcome in women with first trimester vaginal bleeding and in women who did not experience \\
first trimester vaginal bleeding.
\end{tabular}

\section{MATERIALS AND METHODS}

This descriptive comparative study was conducted on pregnant women attending the antenatal outdoor patient, Department of KG Hospital, Coimbatore, between January 2010 and December 2011. The complications and pregnancy outcome in women who experienced first trimester vaginal bleeding were compared with those in women who did not experience vaginal bleeding in first trimester. The women were followed up for spontaneous abortion, preeclampsia, placental abruption and pre-labour rupture of membranes.

\section{RESULTS}

In the control group, 10 cases (13\%) had spontaneous abortion. In study group, 22 cases (29\%) had spontaneous abortion. The Odds ratio (OR) was 2.875 (95\% confidence interval $1.175-7.156$ ). The ' $p$ ' value was $<0.05$, which was significant. In the control group, no case of preeclampsia was encountered. In the study group, 4 of the 53 cases (7.5\%) had preeclampsia. The OR was 11.909 (95\% confidence interval $0.626-226.4)$. The ' $p$ ' value was $<0.05$, which was significant. In the control group, 1 out of the 65 cases $(2 \%)$ had placental abruption compared to 3 out of 53 cases $(6 \%)$ in the study group. The OR was 3.84 (95\% confidence interval 0.340 - 97.277). The ' $p$ ' value was non-significant. In the control group, there were 4 (6\%) cases of PPROM compared to 10 $(19 \%)$ cases in the study group. The OR was 3.5479 (95\% confidence interval $1.043-12.054)$. The ' $p$ ' value was < 0.05, which was significant.

\section{CONCLUSION}

From the above study, we found that women who experience first trimester vaginal bleeding are more likely to have spontaneous abortion, preeclampsia, placental abruption and preterm pre-labour rupture of membranes.

\section{KEYWORDS}

First Trimester Vaginal Bleeding, Threatened Abortion, Spontaneous Abortion, Preeclampsia, Placental Abruption, Preterm PreLabour Rupture of Membranes.

HOW TO CITE THIS ARTICLE: Kangjam P, Baghel S, Akoijam U. Study of maternal outcome in women with first trimester vaginal bleeding- a comparative analysis. J. Evolution Med. Dent. Sci. 2018;7(07):919-921, DOI: 10.14260/jemds/2018/209

\section{BACKGROUND}

One of the most common obstetric problems occurring in first trimester is vaginal bleeding. It accounts for majority of admissions and it is a very common reason for ultrasound examination in early pregnancy. First trimester vaginal bleeding occur in about $25 \%$ of all pregnant women. Many diagnostic possibilities can be considered in these women with vaginal bleeding.

'Financial or Other Competing Interest': None.

Submission 13-01-2018, Peer Review 31-01-2018,

Acceptance 03-02-2018, Published 12-02-2018.

Corresponding Author:

Phalguni Kangjam,

C/o. Dr. Kangjam Sanajaoba Singh,

Ningthemkon,

Opp. St. Paul's Church,

Kwakeithel, Imphal,

Manipur.

E-mail: drkphalguni@gmail.com DOI: $10.14260 /$ jemds $/ 2018 / 209$

\section{(c) $(1) \Theta$}

About half of these women who experience vaginal bleeding will continue their pregnancies and the other half will experience an abortion. The risk of abortion is substantially lower if the foetal cardiac activity was visualised.

Assessment of the cause and prognosis of each patient should be done by clinical history, pelvic examination and ultrasound examination. Ultrasound examination is an important non-invasive modality to evaluate the causes of first trimester bleeding, prognosticate and predict the status of abnormal pregnancy. By far, bleeding during the current pregnancy has been the most predictive risk factor for pregnancy loss.

In this study, we have compared the maternal outcome in patients with first trimester vaginal bleeding and in patients who did not have vaginal bleeding in first trimester. This study was undertaken with the purpose to find out if vaginal bleeding in first trimester is associated with adverse maternal outcome. 


\section{MATERIALS AND METHODS}

It is a descriptive comparative study done on antenatal patients attending Obstetrics Outpatient Department of KG Hospital, Coimbatore between January 2010 and December 2011. A total of 75 antenatal women who had first trimester vaginal bleed and 75 women who did not have first trimester vaginal bleeding were selected for the study out of all antenatal patients as per the inclusion and exclusion criteria and followed up till delivery and immediate postnatal period. The inclusion and exclusion criteria were same, both for the study and control groups except for the first trimester vaginal bleeding episodes in women included in the study group. All women who had first trimester vaginal bleeding and willing to be included in the study were enlisted to be the study group. An equal number of women who did not experience first trimester vaginal bleeding were selected to constitute the control group. Both groups were matched for age and socio-economic status. The concurrence of medico-legal and ethical committee and research and development committee of the hospital was obtained prior to the study.

\section{Inclusion Criteria for the Study Group}

Women who experienced first trimester vaginal bleeding with the following conditions were included in the study group-

1. Singleton pregnancy.

2. Non-anomalous pregnancy.

3. No previous scar on uterus.

4. Vertex presentation.

5. Patient's willingness to be included in the study.

\section{Exclusion Criteria for the Study Group}

Women with first trimester vaginal bleeding with any of the following conditions were not included in the study group-

1. Post-dated pregnancy.

2. History of recurrent pregnancy loss.

3. Placenta previa, fibroid cervix, fibroid uterus.

4. Active Herpes simplex infection.

5. Medical disorders in the antenatal women- diabetes mellitus, epilepsy, hypertension, asthma etc.

\section{Inclusion Criteria for the Control Group}

Women who did not experience first trimester vaginal bleeding with the following conditions were included in the control group-

1. Singleton pregnancy.

2. Non-anomalous pregnancy.

3. No previous scar on uterus.

4. Vertex presentation.

5. Patient's willingness to be included in the study.

\section{Exclusion Criteria for the Control Group}

Women who did not have first trimester vaginal bleeding with any of the following conditions were not included in the control group-

1. Post-dated pregnancy.

2. History of recurrent pregnancy loss.

3. Placenta previa, fibroid cervix, fibroid uterus.

4. Active Herpes simplex infection.

5. Medical disorders in the antenatal women- diabetes mellitus, epilepsy, hypertension, asthma etc.
The women in both the groups were followed up for outcomes of spontaneous abortion, preeclampsia, placental abruption and pre-labour rupture of membranes. The results were then compared. The differences in quantitative variables between groups were assessed by means of the unpaired ' $t$ ' test. The chi-square test was used to assess differences in categoric variables between the groups. The Odds ratio (OR) was calculated to assess the groups. A ' $\mathrm{p}$ ' value of $<0.05$ using a two-tailed test was taken as being of significance for all statistical tests. All data were analysed with a statistical software package (SPSS, version 13.0 for windows).

\section{RESULTS}

In the control group, 10 cases (13\%) had abortion. In study group, 22 cases $(29 \%)$ had abortion. The OR was 2.875 (95\% confidence interval $1.175-7.156)$. The 'p' value was $<0.05$, which was significant.

In the control group, no case of preeclampsia was encountered. In the study group, 4 of the 53 cases (7.5\%) had preeclampsia. The OR was 11.909 (95\% confidence interval 0.626 - 226.4). The ' $p$ ' value was $<0.05$, which was significant.

In the control group, 1 out of 65 cases $(2 \%)$ had placental abruption compared to 3 out of 53 cases $(6 \%)$ in the study group. The OR was 3.84 (95\% confidence interval 0.340 97.277). The ' $p$ ' value was non-significant.

In the control group, there were $4(6 \%)$ cases of PPROM compared to $10(19 \%)$ cases in the study group. The OR was 3.5479 (95\% confidence interval 1.043 - 12.054). The ' $\mathrm{p}$ ' value $<0.05$, which was significant.

\begin{tabular}{|c|c|c|}
\hline & \multicolumn{2}{|c|}{ Group } \\
\hline Abortion & Study & Control \\
\hline Yes & 22 & 10 \\
\hline No & 53 & 65 \\
\hline Total & $\mathbf{7 5}$ & $\mathbf{7 5}$ \\
\hline \multicolumn{2}{|c|}{ Spontaneous Abortion } \\
\hline
\end{tabular}

\begin{tabular}{|c|c|c|}
\hline & \multicolumn{2}{|c|}{ Group } \\
\hline Preeclampsia & Study & Control \\
\hline Yes & 4 & 0 \\
\hline No & 49 & 65 \\
\hline Total & $\mathbf{5 3}$ & $\mathbf{6 5}$ \\
\hline \multicolumn{3}{|c|}{ Preeclampsia } \\
\hline
\end{tabular}

\begin{tabular}{|c|c|c|}
\hline & \multicolumn{2}{|c|}{ Group } \\
\hline Placental Abruption & Study & Control \\
\hline Yes & 3 & 1 \\
\hline No & 50 & 64 \\
\hline Total & $\mathbf{5 3}$ & $\mathbf{6 5}$ \\
\hline \multicolumn{2}{|c|}{ Placental Abruption } \\
\hline
\end{tabular}

\begin{tabular}{|c|c|c|}
\hline & \multicolumn{2}{|c|}{ Group } \\
\hline PPROM & Study & Control \\
\hline Yes & 10 & 4 \\
\hline No & 43 & 61 \\
\hline Total & $\mathbf{5 3}$ & $\mathbf{6 5}$ \\
\hline \multicolumn{2}{|c|}{ Preterm Prelabour Rupture of Membranes } \\
\hline
\end{tabular}

\section{DISCUSSION}

First trimester vaginal bleeding is an alarming event that generates significant concerns in both patient and doctor. According to past studies, it occurs in about $25 \%$ of all 
pregnant women. Many diagnostic possibilities can be considered. Although, many of these pregnancies continue, they are associated with many maternal adverse outcomes.

In the study group, 22 of the 75 antenatal women (30\%) had spontaneous abortions. Only 10 of the 75 antenatal women $(13 \%)$ in the control group had spontaneous abortion. The ' $p$ ' value was less than 0.05 , which was significant. The Odds ratio was 2.875 (95\% confidence interval 1.175 - 7.156). The results of our study are in coherence with studies by Reem Hasan et al, ${ }^{1}$ Gracia C R et $\mathrm{al}^{2}$ Basama FM et al, ${ }^{3}$ Joshua L Weiss et $\mathrm{al}^{4}$ and Johns Jemma et al. ${ }^{5}$

In our study, the incidence of preeclampsia was higher in the study group $(7.5 \%)$ than in the control group $(0.0 \%)$. The 'p' value was less than 0.05 , which was significant. The Odds ratio was 11.909 (95\% confidence interval 0.0626 - 226.4). The findings of our study correlated well with the studies by $\mathrm{R}$ Van Oppenraaij et $\mathrm{al}^{6}$, Joshua L Weiss et $\mathrm{al}^{4}$ and Bimsara $\mathrm{H}$ Perera et al. ${ }^{7}$

In our study, 3 out of $53(6 \%)$ women had placental abruption in the study group. In the control group, 1 out of 65 (2\%) women had placental abruption. Even though the 'p' value was not statistically significant, there was marginal increase in the incidence of placental abruption in the study group. The odds ratio was 3.840 (95\% confidence interval 0.340 - 97.277). As our study was conducted in a tertiary care hospital, the expert care and stringent follow-up of high risk patients with folic acid supplementation, hormonal support and good nutrition might be the reason for the statistically insignificant association found between first trimester vaginal bleeding and placental abruption. The other reason might be the small sample size. The following studies support the significant association of first trimester vaginal bleeding and placental abruption: R Van Oppenraaij et al, ${ }^{6}$ Varsha Mulik et al, ${ }^{8}$ Joshua L Weiss et $\mathrm{al}^{4}{ }^{4} \mathrm{~F}$ Davari-Tanha et $\mathrm{al}^{9}$ and Bimsara H Perera et al. ${ }^{7}$

In our study, 10 out of 53 (19\%) antenatal women who had vaginal bleeding in the first trimester had preterm premature rupture of membranes. In contrast, only 4 out of $65(6 \%)$ women who did not experience first trimester vaginal bleeding had preterm premature rupture of membranes. The difference was statistically significant, as the 'p' value was less than 0.05 . The odds ratio was 3.5479 (95\% confidence interval 1.043 - 12.054). The findings of our study are in coherence with the results of studies by $\mathrm{R}$ Van
Oppenraaij et al, ${ }^{6}$ Weiss JL et $\mathrm{al}^{4}{ }^{4}$ Johns Jemma et $\mathrm{al}^{5}$ and $\mathrm{F}$ Davari-Tanha et al. ${ }^{9}$

\section{CONCLUSION}

In conclusion, the first trimester vaginal bleeding does not necessarily lead to spontaneous abortion. On the other hand, it is certainly associated with impaired pregnancy outcome. It appears to be an independent risk factor for obstetrical problems.

\section{REFERENCES}

[1] Hasan R, Baird DD, Herring AH, et al. Association between first-trimester vaginal bleeding and miscarriage. Obstet Gynecol 2009;114(4):860-7.

[2] Gracia CR, Sammel MD, Chittams J, et al. Risk factors for spontaneous abortion in early symptomatic firsttrimester pregnancies. Obstet Gynecol 2005;106(5 Pt 1):993-9.

[3] Basama FM, Crosfill F, et al. The outcome of pregnancies in 182 women with threatened miscarriage. Archives of Gynaecology and Obstetrics 2004;270(2):86-90.

[4] Weiss JL, Malone FD, Vidaver J, et al. Threatened abortion - a risk factor for poor pregnancy outcome, a population-based screening study. Am J Obstet Gynecol 2004;190(3):745-50.

[5] Johns J, Jauniaux E. Threatened miscarriage as a predictor of obstetric outcome. Obstet Gynecol 2006;107(4):845-50.

[6] Van Oppenraaij R, Jauniax E, Christiansen OB, et al. Predicting adverse obstetric outcome after early pregnancy events and complications: a review. Human Reprod Update 2009;15(4):409-21.

[7] Perera BH, De Silva AP, Perera H. A case control study on the effect of threatened miscarriage on selected pregnancy outcomes. Sri Lanka J Obstet Gynecol 2009;31(1):34-8.

[8] Mulik V, Bethel J, Bhal K. A retrospective populationbased study of primigravid women on the potential effect of threatened miscarriage on obstetric outcome. J Obstet Gynecol 2004;24(3):249-53.

[9] Davari-Tanha F, Shariat M, Kaveh M, et al. Threatened abortion: a risk factor for poor pregnancy outcome. Acta Medica Iranica 2008;46(4):314-20. 